\title{
Association of polypharmacy with postural instability and impaired balance in community-dwelling older adults in Turkey
}

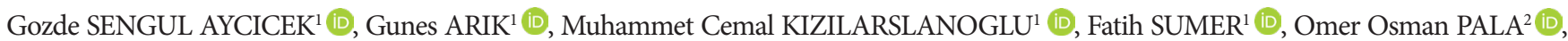
Busra CAN $^{1}$ (D), Ozgur KARA ${ }^{1}$ (D), Selda BASAR ${ }^{2}$ (D), Zekeriya ULGER ${ }^{1}$ (D)

${ }^{1}$ Division of Geriatrics, Department of Internal Medicine, School of Medicine, Gazi University, Ankara, Turkey.

${ }^{2}$ Department of Physical Therapy and Rehabilitation, School of Health Sciences, Gazi University, Ankara, Turkey.

\author{
Corresponding Author: Gozde SENGUL AYCICEK \\ E-mail: gzdsengul@gmail.com
}

Submitted: 19.07.2020 Accepted: 30.09.2020

\begin{abstract}
Objective: Polypharmacy, an important geriatric syndrome, has been shown to be an independent risk factor for falling. However, the data about effects of polypharmacy on balance is lacking. We aimed to evaluate the effects of polypharmacy and inappropriate drug usage on balance in older adults.

Patients and Methods: Fifty-one patients using $\geq 5$ drugs and 50 patients using $<5$ drugs were included in the study. Inappropriate drug usage of the patients was evaluated by Beers criteria. Postural stability and risk of falling was investigated by using Biosway Portable Balance System (BPBS). Activities and functional status of the patients were assessed by using Short Physical Performance Battery (SPPB) and Activities Specific Balance Confidence Scale (ABC). All patients underwent comprehensive geriatric assessment. Results: Age, gender, hand grip strength, SPPB scores of the patients were similar between polypharmacy and control groups (all had $\mathrm{p}>0.05)$. ABC score was higher in polypharmacy group than control $(\mathrm{p}<0.01)$. Overall, anterior-posterior, medial-lateral stability index and eyes closed firm surface scores detected in BPBS were higher, indicating worse stability in the polypharmacy group than control $(\mathrm{p}<0.05)$. Limit of stability score was lower in the polypharmacy group than control $(\mathrm{p}=0.03)$. Rates of polypharmacy and inappropriate drug usage were higher in patients with a history of falling than without $(\mathrm{p}<0.01, \mathrm{p}<0.01$, respectively). In multivariate analysis model, polypharmacy was found to be an independently correlated parameter for impaired balance (OR 24.31; 95\%CI 3.05193.91; $\mathrm{p}<0.01)$.

Conclusion: This study has demonstrated that polypharmacy might be a related factor for impaired balance. Struggling with polypharmacy and inappropriate drug usage should be one of the most important part of comprehensive geriatric assessment.

Keywords: Balance, Elderly, Falling, Polypharmacy
\end{abstract}

\section{INTRODUCTION}

Approximately one third of the patients over 65 years have experienced at least one falling every year and about $10 \%$ of the cases result in serious injury causing major morbidity and mortality in this population $[1,2]$. The health expenditures due to fall-related injuries are progressively increasing $[3,4]$. Polypharmacy is generally defined as using 5 or more drugs and a number of drugs have been shown to be associated with an increased risk of falling in geriatric population [5-7]. As well as the number of the drugs, inappropriate medications are also important in older adults that may lead to increased risk of drug-drug interactions and various side effects [8-10].

Postural stability is a complex process that requires the combination of multiple neurological sensory and motor components to maintain the body balance [11]. Maintaining postural stability diminishes with age and this facilitates falls in older adults [12]. Biosway Portable Balance System (Biodex Inc. Shirley, New York) (BPBS) is a device that assesses balance and its sub-parameters such as postural stability, limit of stability (LOS) and risk of fall via modified Clinical Test of Sensory Integration and Balance (m-CTSIB). The system provides valid, reliable, and repeatable objectives measures of a patient's neuromuscular control and ability to balance on a firm and/or unstable surface. There are some studies showing the predictive effect of BPBS on risk of falling for elderly population in literature [13]. This system enables the objective assessment of the balance and consists of a balance platform connected to computer software. Performances of the patients were assessed and the computer gives automatically goal values for each person.

How to cite this article: Aycicek Sengul G, Arik G, Kizilarslanoglu M C, Sumer F, Pala O O, Can B, Kara O, Basar S, Ulger Z. Association of polypharmacy with postural instability and impaired balance in community-dwelling older adults in Turkey. Marmara Med J; 34(1):12-17, doi: 10.5472/marumj.869538 
Although, the association between polypharmacy and falling risk is well known, the data about the association between polypharmacy and balance problems detected with BPBS is lacking. In the light of this knowledge, this study was carried out to evaluate the effects of polypharmacy and inappropriate drug usage on balance problems detected by using BPBS and falls in elderly patients.

\section{PATIENTS and METHODS}

Patients aged 65 years and over who applied to the geriatric outpatient clinic at a university hospital between 2015 and 2016 were included in this study. The participants were divided into two groups as 51 patients using 5 or more drugs as study group and 50 patients using less than 5 drugs as control group. All patients underwent comprehensive geriatric assessment including Mini Nutritional Assessment - Short Form [14], Katz activities of daily living [15], Lawton Brody instrumental activities of daily living [16], Mini Mental State Examination [17], Yesavage Depression Scale [18] and clock drawing tests. Hand grip strength was measured by grip strength dynamometer, (Grip D produced by Takei / Made in Japan) with dominant hand. Measurements were repeated for three times after 10 second intervals and maximum hand grip strength value was recorded. The number of drugs and the comorbidities of the participants were also recorded. Inappropriate medication usage was identified by using Beers criteria [8-10]. All patients were included in the study after their informed consents were obtained. The exclusion criteria were history of orthopedic surgery (presence of prosthesis), vestibular, neurological and rheumatologic diseases, diabetic neuropathy documented both symptoms and electromyography, bone fracture due to falls in the last 6 months, having severe joint deformity and not cooperating to BPBS measurement.

\section{Assessment of risk of falling, postural stability and limit of stability}

Risk of falling, postural stability and LOS were assessed by using BPBS (Biodex Inc. Shirley, New York) [19]. This system enables the objective assessment of the balance and consists of a balance platform connected to computer software. Each participant was given the information about the test and one trial evaluation was performed before recording the results. The patients participated in the balance assessment with bare feet. The position of the foot was determined by adjusting the position in which an individual can stand in balance with minimal effort. The coordinate location on the platform, age and height of the participants were recorded to the device. The risk of fall was assessed with $\mathrm{m}$-CTSIB test, in 4 conditions as standing on a firm and foam surface with eyes open and closed (preferred test protocol: eyes open firm surface, eyes closed firm surface, eyes open foam surface and eyes closed foam surface). The duration of each condition was 20 seconds. The higher Sway Index score points out the more unstable patients. Postural stability was evaluated by the assessment of the patients' ability to keep a moving point on the screen of the BPBS. The test was repeated for three times with each part taking 20 seconds. Overall stability index (OSI), anterior-posterior stability index (APSI) and mediallateral stability index (MLSI) scores were measured. Higher values indicate worse stability. LOS was measured by assessment of ability of patient moving through a blinking ball and back to the screen by shifting the body weight on the platform. Performances of the patients were assessed according to the LOS scores. The test was repeated three times. The computer gives automatically goal values for each person's LOS test. The system reliability for postural stability and LOS were tested with 25 healthy elderly volunteers in bilateral standing (two sessions on consecutive weeks).

\section{Assessment of physical activity and fear of falling}

Activities and functional status of the patients were assessed by using Short Physical Performance Battery (SPPB) [20]. The scores ranged from 0 (worst performance) to 12 (best performance). Activities Specific Balance Confidence Scale $(\mathrm{ABC})$ was also performed. Patients were asked 16 questions in this scale to indicate their level of confidence in doing the activity without losing their balance or becoming unsteady. They selected one of the percentage points on the scale from $0 \%$ to $100 \%$ [21]. Arithmetic mean of the total score was taken.

\section{Biochemical evaluation}

Fasting plasma glucose, high density lipoprotein, low density lipoprotein, total cholesterol, triglyceride, blood urea nitrogen, creatinine, sodium, potassium, calcium, total protein, albumin, thyroid stimulating hormone, free $\mathrm{t} 4$, alanine aminotransferase, aspartate aminotransferase, gamma-glutamyl transferase, alkaline phosphatase, bilirubin, vitamin B12, folic acid, $25(\mathrm{OH})$ vitamin $\mathrm{D}, \mathrm{C}$ reactive protein levels, erythrocyte sedimentation rate and complete blood count were measured.

\section{Ethics}

Ethical approval for the research was obtained from the Ethics Committee of Kecioren Training and Research Hospital, Ankara, in 2015 and informed consent was obtained from each participant conforming to the Helsinki Declaration.

\section{Statistical Analysis}

Statistical analysis was performed by using Statistical Package for Social Sciences (SPSS) for windows 15.0 software. Numerical parameters were assessed by histogram and Kolmogorov Smirnov test to evaluate whether the variables had normally distribution or not. Categorical variables were presented as frequencies and percentage. Comparison of continuous numerical parameters between two groups was done by using Student's T or Mann-Whitney U tests according to the distribution of the parameters as normal or skew distribution, respectively. Categorical parameters were compared with Chisquare test. Detection of the independent associated factors affecting falls in geriatric patients was made by binary logistic regression analysis. In the regression analysis model, the parameters that were different ( $p$ value lower than 0.05 ) between patients with and without history of falling in the previous year 
before the study conducted were included. Receiver Operating Characteristic (ROC) analysis was applied to detect the optimum drug number which may increase the falling in geriatric patients. $P$ value $<0.05$ was considered as statistically significant.

\section{RESULTS}

Median age of the study population was 72 years (min-max: 65-86) and $55.4 \%$ of patients were female. Age, sex, hand grip strength and usage of walking aid were similar between groups. Mean body mass index (BMI) of patients in the polypharmacy group was higher than control group $(\mathrm{p}<0.01)$. SPPB total scores were similar between groups. ABC scores were lower in the polypharmacy group $(\mathrm{p}=0.01)$. The demographic characteristics, clinical features and laboratory parameters of patients are summarized in Table I.

Table I. Demographic characteristics, co-morbidities and baseline laboratory findings of the patients

\begin{tabular}{|c|c|c|c|c|}
\hline & $\begin{array}{c}\text { All groups } \\
\mathbf{n}=101\end{array}$ & $\begin{array}{l}\text { Polypharmacy } \\
\text { group } \\
n=51\end{array}$ & $\begin{array}{c}\text { Control group } \\
\mathrm{n}=50\end{array}$ & $\underset{\text { value }}{p}$ \\
\hline Age, years & $72(65-86)$ & $72(65-86)$ & $71(65-85)$ & 0.09 \\
\hline Sex (\%Female) & 55.4 & 52.9 & 58 & 0.61 \\
\hline BMI, kg/m2 & $29.6 \pm 4.4$ & $30.8 \pm 4.1$ & $28.5 \pm 4.5$ & $<0.01$ \\
\hline $\begin{array}{l}\text { Handgrip } \\
\text { strength, kg }\end{array}$ & $24.8 \pm 8.8$ & $23.9 \pm 9.5$ & $25.6 \pm 8.1$ & 0.35 \\
\hline $\begin{array}{l}\text { Mobilization (\% } \\
\text { walking aid) }\end{array}$ & 5.9 & 5.9 & 6 & 1.00 \\
\hline $\begin{array}{l}\text { History of falling } \\
(\%)\end{array}$ & 18.8 & 35.3 & 2.0 & $<0.01$ \\
\hline SPPB score & $8.4 \pm 1.7$ & $8.1 \pm 1.5$ & $8.7 \pm 1.8$ & 0.08 \\
\hline $\mathrm{ABC}$ score & $85.3(0-100)$ & $91.83(40-100)$ & $80.67(0-100)$ & $<0.01$ \\
\hline \multicolumn{5}{|l|}{$\begin{array}{l}\text { Co-morbidities, } \\
\text { n (\%) }\end{array}$} \\
\hline Hypertension & $68(67.3)$ & $47(92.2)$ & $21(42.0)$ & $<0.01$ \\
\hline Diabetes mellitus & $35(34.7)$ & $35(68.6)$ & $0(0.0)$ & $<0.01$ \\
\hline $\begin{array}{l}\text { Coronary artery } \\
\text { disease }\end{array}$ & $12(11.9)$ & $11(21.6)$ & $1(2.0)$ & $<0.01$ \\
\hline \multicolumn{5}{|l|}{$\begin{array}{l}\text { Biochemical } \\
\text { parameters }\end{array}$} \\
\hline $\begin{array}{l}\text { Fasting plasma } \\
\text { glucose }(m g / d L)\end{array}$ & $100(70-294)$ & $113(78-294)$ & $94(70-198)$ & $<0.01$ \\
\hline$H b(g / d L)$ & $13.3 \pm 1.6$ & $13.04 \pm 1.4$ & $13.60 \pm 1.8$ & 0.08 \\
\hline $\begin{array}{l}\text { Vitamin B12 (pg/ } \\
m L)\end{array}$ & $376(117-1887)$ & $376(117-1887)$ & $359(164-1823)$ & 0.82 \\
\hline $\begin{array}{l}25 \mathrm{OH} \text { vitamin } D \\
(\mu \mathrm{g} / \mathrm{L})\end{array}$ & $21.4(5.9-79.6)$ & $22.3(5.9-79.6)$ & $19.1(9.0-44.7)$ & 0.32 \\
\hline $\mathrm{TSH}(\mathrm{mIU} / \mathrm{mL})$ & $1.8(0.5-14.0)$ & $1.8(0.5-9.7)$ & $1.8(0.5-14.0)$ & 0.90 \\
\hline
\end{tabular}

BMI: Body Mass Index, SPPB: Short Physical Performance Battery, ABC: Activities Specific Balance Confidence Scale, Hb: Hemoglobin, TSH: Thyroid stimulating hormone. The numerical parameters are shown as mean \pm standard deviation or median (min-max) according to the distribution pattern of the variables.

The rate of inappropriate drug usage according to the Beers criteria was $22.8 \%$ in the study population and only $4 \%$ of the study population was using at least one drug that may increase the risk of falling. Rate of previous history of falling was higher in the polypharmacy group compared to control (35.3\% versus $2 \%, \mathrm{p}<0.001)$. Comprehensive geriatric assessment scores are shown in Table II.

Table II. The results of comprehensive geriatric assessment test parameters between study and control groups

\begin{tabular}{llll|} 
& \multicolumn{1}{c}{$\begin{array}{c}\text { Polypharmacy group } \\
\mathbf{n = 5 1}\end{array}$} & $\begin{array}{c}\text { Control group } \\
\mathbf{n = 5 0}\end{array}$ & p value \\
\hline Katz ADL & $6(5-6)$ & $6(5-6)$ & $>0.05$ \\
Lawton-Brody IADL & $8(5-8)$ & $8(4-8)$ & $>0.05$ \\
\hline MNA-SF & $14(10-14)$ & $14(5-14)$ & 0.046 \\
MMSE & $30(25-30)$ & $29(25-30)$ & 0.014 \\
\hline YDS & $0(0-8)$ & $2(0-11)$ & $<0.001$ \\
6 m gait speed, m/sn & $5(3.1-13.2)$ & $7(3.5-28.1)$ & $<0.001$ \\
\hline Hand grip strength, kg & $25.6 \pm 8.1$ & $23.9 \pm 9.4$ & $>0.05$ \\
\hline
\end{tabular}

ADL: Activities of daily living, IADL: Instrumental activities of daily living, MNA-SF: mininutritional assessment-short form, MMSE: minimental state examination, YDS: Yesavage depression scale, The numerical parameters are shown as mean \pm standard deviation or median (min-max) according to the distribution pattern of the variables.

When the patients were classified according to the history of falling, the rate of polypharmacy was seen to be higher in the patients with history of falling than without $(94.7 \%$ versus the $40.2 \%, \mathrm{p}<0.01)$. The incidence of hypertension, diabetes mellitus and hypothyroidism were found to be higher in patients with a history of falling than without $(\mathrm{p}=0.02, \mathrm{p}<0.01$ and $\mathrm{p}=$ 0.04 , respectively). Inappropriate drug usage, according to Beers criteria was also more frequent in patients with history of falling than without $(52.6 \%$ versus $15.9 \%, \mathrm{p}<0.01)$.

Impaired balance and increased risk of falling were observed in the polypharmacy group. Eyes closed firm surface score was higher in the polypharmacy group than control $(p=0.042)$. All postural stability index scores were found to be higher in the polypharmacy group compared to control $(\mathrm{p}<0.01, \mathrm{p}=0.03$, $\mathrm{p}<0.01$, respectively). LOS score was significantly lower in the polypharmacy group (34 min-max: $15-81$ vs. 39 min-max: 18$60, \mathrm{p}=0.03)$. Results of BPBS are shown in Table III.

Table III. Comparison of BPBS results between polypharmacy and control groups

\begin{tabular}{lccc} 
& Polypharmacy group & Control group & P value \\
\hline EOFS & $0.53(0.26-1.81)$ & $0.50(0.25-1.13)$ & 0.19 \\
ECFS & $0.82(0.45-2.58)$ & $0.70(0.30-1.87)$ & $\mathbf{0 . 0 4}$ \\
EOSS & $1.23(0.72-4.14)$ & $1.16(0.75-2.65)$ & 0.50 \\
ECSS & $2.96(1.87-4.73)$ & $2.94(1.42-5.52)$ & 0.66 \\
\hline OSI & $0.50(0.20-4.30)$ & $0.40(0.20-1.0)$ & $<\mathbf{0 . 0 1}$ \\
APSI & $0.40(0.10-3.10)$ & $0.30(0.10-1)$ & $\mathbf{0 . 0 3}$ \\
\hline MLSI & $0.20(0.0-2.90)$ & $0.20(0.0-0.70)$ & $<\mathbf{0 . 0 1}$ \\
LOS & $34(15-81)$ & $39(18-60)$ & $\mathbf{0 . 0 3}$ \\
\hline
\end{tabular}

EOFS: eyes open firm surface ECFS: eyes closed firm surface EOSS: eyes open soft surface ECSS: eyes closed soft surface OSI: overall stability index APSI: anterior-posterior stability index MLSI: medial-lateral stability index LOS: limits of stability. All the variables are shown as median (min-max) according to the distribution pattern. 
In multivariate analysis model, polypharmacy was found to be an independently correlated parameter for falling (OR 24.31; 95\%CI 3.05-193.91; $\mathrm{p}<0.01$ ) (Table IV). As a result of ROC analysis, $>2$ drugs use was identified as a cut-off for fall risk $(94.7 \%$ sensitivity and $59.76 \%$ specificity, $35.3 \%$ positive predictive and $98 \%$ negative predictive value, AUC 0.747, $\mathrm{p}<0.05)$.

Table IV. The independently related factors of impaired balance are shown in these multivariate analysis models.

\begin{tabular}{|c|c|c|c|c|}
\hline \multirow[b]{2}{*}{ Parameters } & \multicolumn{3}{|c|}{ 95\% Confidence Interval } & \multirow[b]{2}{*}{$p$ value } \\
\hline & OR & Lower limit & Upper limit & \\
\hline \multicolumn{5}{|l|}{ Model $1^{\star}$} \\
\hline Polypharmacy & 24.31 & 3.05 & 193.91 & 0.003 \\
\hline \multicolumn{5}{|l|}{ Model 2** } \\
\hline Diabetes mellitus & 7.89 & 1.99 & 31.34 & 0.003 \\
\hline Inappropriate drug usage & 11.05 & 2.39 & 51.10 & 0.002 \\
\hline
\end{tabular}

${ }^{*}$ Model 1: The parameters those had $p$ value lower than 0.05 when comparing between patients with and without falling history were included in this multivariate model. The parameters were polypharmacy, hypertension, diabetes mellitus, hypothyroid, body mass index, walking speed, eyes closed firm surface, overall stability, anterior-posterior stability, medial-lateral stability and limits of stability indexes, mini-nutritional assessment-short form, mini-mental state examination, Yesavage geriatric depression scale and fasting blood glucose. ** Model 2: Instead of polypharmacy, inappropriate drug usage according to Beers criteria was included in this multivariate analysis model.

\section{DISCUSSION}

In this study, we have found that polypharmacy would be a related factor for impaired balance and falling in the geriatric population regardless using of a drug that may increase the risk of falling. Additionally, rate of polypharmacy and incidence of inappropriate drug usage were higher in patients with falling history. To our knowledge, this is the first study examining the relationship between polypharmacy and balance with BPBS in older adults.

Falls are one of the major health issues among the older population. Falls are often accompanied by complications such as fractures, long term disability, loss of independence and increased risk of mortality. Polypharmacy is one of the most significant fall risk factor in the older adults [22]. Recently, Zaninotto, et al., showed that the risk of hospitalization due to a fall increased with polypharmacy [23]. In this study, similar with the literature, we have found a positive correlation between polypharmacy and falling risk. Kojima, et al., mentioned that taking 5 or more drugs was a significant risk for falls [24]. Our results have shown that taking two or more drugs is significantly related with increased fall risk in geriatric patients. Additionally, in our study, it has been found that behind the polypharmacy, inappropriate drug use is also an important related factor for falls in elderly population. Especially, serotonin reuptake inhibitors, tricyclic antidepressants, neuroleptics, benzodiazepines, anticonvulsants, class $1 \mathrm{~A}$ antiarrhythmic drugs, digoxin and diuretics are associated with increased falls $[6,25]$. We could not find a relation between drug subclasses and fall risk. This finding may be derived from small sample size of the study.

We found that, in the polypharmacy group $\mathrm{ABC}$ scores were lower and rate of previous history of fall was higher than control. Previously, researchers found an inverse relation between balance confidence and impaired balance [2]. Also, communitydwelling older adults with fear of falling have demonstrated decreased performance on measures of balance and gait [27]. Lajoie, et al., showed that those individuals with a fall history were more affected by the fear of falling and more restricted in daily activities [28]. Similar to the literature, we found impaired balance and low gait speed in the polypharmacy group.

Body mass index values were higher in the polypharmacy group. Obesity prevalance was increased among geriatric population in recent years. Both aging and obesity could result in multiorgan dysfuntion that leads to increased chronic diseases and polypharmacy.

Multimorbidities are common in the elderly and these lead to increase in the risk of polypharmacy and related adverse drug reactions. The incidence of chronic diseases such as hypertension, diabetes mellitus and hypothyroidism were found to be higher in polypharmacy group and patients with a history of falling. Although, diabetes mellitus incidence was higher, diabetic neuropathy documented both by symptoms and electromyography did not exist in the polypharmacy group. Additionally, model 1 shows that the polypharmacy is an independently associated factor for impaired balance in the elderly patients irrespective of having diabetes mellitus, hypertension, body mass index, etc.

In older adults, polypharmacy effects many disease processes, with balance function being one of the most susceptible. Evaluation of the older patients with a balance disorder is critical for these patients [29]. To assess balance situation, postural stability of the patients was evaluated by BPBS [19]. In our study, OSI scores were found to be higher in patients with polypharmacy. OSI is believed to be the most reliable indicator of postural stability and higher scores indicate poorer stability [19]. Hsieh, et al., previously reported that, patients with knee osteoarthritis displayed higher OSI than controls, therefore displayed lower postural stability [30]. In the polypharmacy group, also, sway index, measured at a condition eyes closed firm surface, was higher than control group demonstrating that firm surface might be related with impaired balance. However, in previous studies, soft foam surface has been shown to be related with poor balance assessment results that challenges with our results [31]. This finding may be due to the eyes condition (open or closed) while using the device [32]. In our study, no impaired balance was detected in patients using BPBS device while their eyes open regardless of the characteristics of the surface.

Additionally, our results showed that limits of stability scores were worse in the polypharmacy group. Limit of stability is defined as the maximum angle a person's body can achieve from vertical position without losing balance [19]. Lower LOS values point out the unstable patient. It has been demonstrated that hip muscles strength that contributes to balance is reduced with ankle 
dysfunction. Also, fatigue of ankle plantar flexors and dorsiflexors have shown to significantly influence sway parameters and postural control [33]. Additionally, these authors mentioned that, due to the impairment in the large muscles of the ankle, the smaller muscles of the foot compromise for maintaining the stability. In the elderly as well as polypharmacy, these findings may be due to the sarcopenia in the lower extremity muscles.

The study had several limitations. The information about the falls of the patients was evaluated retrospectively. Prospective analysis including falls history of the patients should be performed with larger studies. This study was not in a longitudinal manner. Secondly, falls were self-reported. Because of that, some of the patients may have not remembered the all fallings. Thirdly, the underlying causes of previous falls history of our patients had not been exactly explored. The reason for that is the assessment of falls was made retrospectively.

In conclusion, polypharmacy is a remarkable problem leading to balance problems and falls in geriatric population. Falls related injuries take great place in health care expenditures. In evaluation of the older adults presenting with balance problems, polypharmacy and inappropriate drug usage should be kept in mind and questioned separately.

\section{Compliance with Ethical Standards}

Ethical Approval: The study protocol was approved by the Ethics Committee of Kecioren Training and Research Hospital, Ankara, in 2015 and informed consent was obtained from each participant conforming to the Helsinki Declaration.

Financial Support: The authors have no relevant financial information to disclose.

Conflict of Information: The authors declare no conflict of interest.

Author Contributions: G. S. A. and Z. U. :Equally contributed to the conception and design of the research, G.S.A. and M. C. K.: Equally contributed to the acquisition and analysis of the data, G.S.A., F. S., O. O. P., B. C. and O. K. : Equally contributed to the interpretation of the data, S. B., and Z. U. : Critically revised the manuscript, G.S.A. and Z. U. : Drafted the manuscript. All authors agree to be fully accountable for ensuring the integrity and accuracy of the work and read and approved the final manuscript.

\section{REFERENCES}

[1] Rubenstein LZ, Josephson KR. The epidemiology of falls and syncope. Clin Geriatr Med 2002; 18: 141-58. DOI: 10.1016/ s0749-0690(02)00002-2

[2] Tinetti ME, Doucette J, Claus E, Marottoli R. Risk factors for serious injury during falls by older persons in the community. J Am Geriatr Soc 1995; 43: 1214-21). doi: 10.1111/j.15325415.1995.tb07396.x

[3] Stevens JA, Corso PS, Finkelstein EA, Miller TR. The costs of fatal and non - fatal falls among older adults. Inj Prev 2006; 12 : 290-5. doi: 10.1136/ip.2005.011015.
[4] Englander F, Hodson TJ, Terregrossa RA. Economic dimensions of slip and fall injuries. J Forensic Sci 1996; 41: 733-46.

[5] Corsinovi L, Bo M, Ricauda Aimonino N, et al. Predictors of falls and hospitalization outcomes in elderly patients admitted to an acute geriatric care unit. Arch Gerontol Geriatr 2009; 49: 142-145. doi: 10.1016/j.archger.2008.06.004

[6] Woolcott JC, Richardson KJ, Wiens MO, et al.Meta - analysis of the impact of 9 medication classes on falls in elderly persons. Arch Intern Med 2009; 169: 1952-60. doi: 10.1001/ archinternmed.2009.357

[7] Laflamme L, Monárrez-Espino J, Johnell K, Elling B, Möller J.Type, number or both? A population base matched case control study on the risk of fall injuries among older people and number of medications beyond fall inducing drugs. PLoS ONE 2015; 10: 1-12. doi:: 10.1371/journal.pone.0123390.

[8] Beers MH, Ouslander JG, Rollingher I, Reuben DB, Brooks J, Beck JC. Explicit criteria for determining inappropriate medication use in nursing home residents. Arch Intern Med 1991;151:1825-32.

[9] Beers MH. Explicit criteria for determining potentially inappropriate medication use by elderly. An update. Arch Intern Med 1997;157:1536.

[10] American Geriatrics Society 2015 Beers Criteria Update Expert Panel. American Geriatrics Society 2015 Updated Beers Criteria for potentially inappropriate medication use in older adults. J Am Geriatr Soc 2015; 63:2227-46. doi: 10.1111/ jgs. 13702

[11] Ryan EE, Rossi MD, Lopez R. The effects of the contract-relax antagonist-contract form of proprioceptive neuromuscular facilitation stretching on postural stability. J Strength Cond Res 2010;24:1888-94. doi: 10.1519/JSC.0b013e3181ddad9d

[12] Shumway-Cook A, Woollacott M, Baldwin M. The effects of cognitive demands on postural sway in young versus older adults (fallers and nonfallers). Neurology Report 1995;19:446.

[13] Khalaj N, Abu Osman NA, Mokhtar AH, Mehdikhani M, Wan Abas WA. Balance and risk of fall in individuals with bilateral mild and moderate knee osteoarthritis. PLoS ONE 2014; 9: 1-7. doi: 10.1371/journal.pone.0092270

[14] Vellas B, Guigoz Y, Garry PJ, et al. The mini nutritional assessment (MNA) and its use in grading the nutritional state of elderly patients. Nutrition 1999; 15: 116-22. doi: 10.1016/ s0899-9007(98)00171-3

[15] Katz S, Ford A. B, Moskowitz R. W, Jackson B. A, Jaffe M. W. Studies of illness in the aged. The index of ADL: a standardized measure of biological and psychosocial function. JAMA.1963; 185: 914-9. doi: 10.1001/jama.1963.030.60120024016.

[16] Lawton MP, Broody EM. Assessment of older people: Selfmaintaining and instrumental activities of daily living. Gerontologist 1969; 9: 179-86.

[17] Folstein MF, Folstein JE, McHugh PR. "Mini Mental State" a practical method for grading the cognitive state of patients for the clinician. J Psychiatr Res 1975; 12: 189-98. doi: 10.1016/0022-3956(75)90026-6 
[18] Yesavage JA, Brink TL, Rose TL, et al. Development and validation of a geriatric depression screening scale. A preliminary report. J Psychiatr Res 1983; 17: 37-49. doi: 10.1016/0022-3956(82)90033-4

[19] Biodex. Biodex balance system: clinical resource manual. Shirley, New York: Biodex Medical System Inc, 1999.

[20] Guralnik JM, Simonsick EM, Ferrucci L,et al., A short physical performance battery assessing lower extremity function: association with self-reported disability and prediction of mortality and nursing home admission. J Gerontol1994: 49: M85-M94. doi: 10.1093/geronj/49.2.m85

[21] Powell LE, Myers AM The activities-specific balance confidence $(\mathrm{ABC})$ scale. JGerontol A Biol Sci Medi Sci 1995;50:M28-M34. doi: 10.1093/gerona/50a.1.m28

[22] Díaz LB, Casuso-Holgado M J, Labajos-Manzanares M T, et al. Analysis of fall risk factors in an aging population living in long-term care institutions in SPAIN: A Retrospective cohort study. Int J Environ Res Public Health 2020;17:7234. doi: 10.3390/ijerph17197234

[23] Zaninotto P, Huang YT, Di Gessa Gt al. Polypharmacy is a risk factor for hospital admission due to a fall: evidence from the English Longitudinal Study of Ageing. BMC Public Health 2020;20:1804. doi: 10.1186/s12889.020.09920-x

[24] Kojima T, Akishita M, Nakamura T, et al. Polypharmacy as a risk for fall occurrence in geriatric outpatients. Geriatr Gerontol Int $2012 ; 12: 425$-30. doi: 10.1111/j.1447-0594.2011.00783.x

[25] Leipzig RM, Cumming RG, Tinetti ME. Drugs and falls in older people: a systematic review and meta-analysis: II.Cardiac and analgesic drugs. J Am Geriatr Soc 1999;47 : 40-50. doi: 10.1111/j.1532-5415.1999.tb01899.x
[26] Nemmers TM, Miller JWJ. Factors influencing balance in healthy community-dwelling women age 60 and older. Geriatr Phys Ther 2008;31:93-100. doi: 10.1519/00139.143.20083103000003

[27] Vellas BJ, Wayne SJ, Romero LJ, Baumgartner RN, Garry PJ. Fear of falling and restriction of mobility in elderly fallers. Age Ageing 1997;26:189-93. doi: 10.1093/ageing/26.3.189

[28] Lajoie Y, Gallagher SP. Predicting falls within the elderly community: comparison of postural sway, reaction time, the Berg balance scale and the Activities-specific Balance Confidence $(\mathrm{ABC})$ scale for comparing fallers and non-fallers. Arch Gerontol Geriatr2004;38:11-26. doi: 10.1016/s01674943(03)00082-7

[29] Eibling D. Balance disorders in older adults. Clin Geriatr Med 2018 ;34(2):175-81. doi: 10.1016/j.cger.2018.01.002

[30] Hsieh RL, Lee WC, Lo MT, Liao WC. Postural stability in patients with knee osteoarthritis: comparison with controls and evaluation of relationships between postural stability scores and International Classification of Functioning, Disability and Health components. Arch Phys Med Rehabil 2013 ;94340-6. doi: 10.1016/j.apmr.2012.09.022.

[31] Fransson PA, Gomez S, Patel M, Johansson L. Changes in multi-segmented body movements and EMG activity while standing on firm and foam support surfaces. Eur J Appl Physiol2007 ;101:81-9doi: 10.1007/s00421.007.0476-x

[32] Stillman BC. Making Sense of rPoprioception: The meaning of proprioception, kinaesthesia and related terms .Physiotherapy 2002;88 : 667-676. doi:10.1016/S0031-9406(05)60109-5

[33] Yaggie JA, McGregor SJ. Effects of isokinetic ankle fatigue on the maintenance of balance and postural limits. Arch Phys Med Rehabil 2002 ;83:224-8. doi: 10.1053/apmr.2002.28032 